Check for updates

Cite this: RSC Adv., 2017, 7, 55547

Received 7th October 2017

Accepted 26th November 2017

DOI: $10.1039 / c 7 r a 11031 f$

rsc.li/rsc-advances

\section{Potential waste from palm empty fruit bunches and
eggshells as a heterogeneous catalyst for biodiesel \\ Potential waste from palm empty fruit bunches and
eggshells as a heterogeneous catalyst for biodiesel production}

\author{
Meilana Dharma Putra, (D) Yuli Ristianingsih, Rinny Jelita, Chairul Irawan (D) \\ and Iryanti Fatyasari Nata (D) *
}

\begin{abstract}
Biodiesel is one of the potential alternative energies produced from a variety of vegetable oils. The utilization of a $\mathrm{CaO} / \mathrm{SiO}_{2}$ catalyst generated from eggshell and palm empty fruit bunch (PEFB) waste for biodiesel production from waste cooking oil was investigated. The optimum silica yield extracted from PEFB was $68.2 \%$ using $10 \% \mathrm{NaOH}(\mathrm{w} / \mathrm{v})$ at $80{ }^{\circ} \mathrm{C}$ for $1 \mathrm{~h}$. Methanol with a mol ratio of 14 to waste cooking oil was used. The presence of a silica support in the $\mathrm{CaO}$ catalyst increased the yield of biodiesel from $78 \%$ to $96 \%$. Three runs of the catalyst led to only a $1 \%$ reduction in biodiesel yield. The utilization of activated PEFB as a support showed a potential result with a biodiesel yield of $83 \%$. The prospective heterogeneous catalysts were also characterized by using XRD, SEM, BET and FT-IR. The developed $\mathrm{CaO} / \mathrm{SiO}_{2}$ stands out as a promising catalyst for biodiesel production due to the utilization of abundant and cheap waste materials. Moreover, a significant yield of biodiesel was obtained using the catalyst; hence, it is feasible to be developed on a larger scale.
\end{abstract}

\section{Introduction}

An increased demand for energy has arisen due to increased industrial development, transportation, and human growth. The availability of conventional energy sources such as petroleum, coal and natural gas will eventually be exhausted. Fuel from renewable energy such as biodiesel is one of the solutions to replace the limited fossil fuels. ${ }^{1}$ On the other hand, the use of fossil fuels can lead to the greenhouse effect from gas emissions and other environmental pollution. Biodiesel is a renewable, sustainable and non-toxic fuel that can reduce the problems of fossil fuel utilization. ${ }^{2}$ The main raw material of biodiesel production is commonly vegetable oils such as palm oil, soy, corn, etc. ${ }^{3}$ However, the use of vegetable oils is less attractive due to its competitiveness with the fulfilment of food requirements. ${ }^{4}$ Currently, researchers are attempting to develop biodiesel production processes from various waste materials, like used cooking oil. Waste cooking oil is an abundant and low-cost material; ${ }^{5}$ however, the high levels of free fatty acids (FFAs) in the oil will be a challenge for researchers.

Biodiesel is generally produced by using homogeneous catalysts such as $\mathrm{NaOH}$ and $\mathrm{KOH} .{ }^{6}$ However, the purification process required is expensive due to the difficulty in handling the separation of the catalyst from the product. ${ }^{1}$ Moreover, the catalyst cannot be recovered for reuse; as a result, it is simply disposed of as waste and causes environmental contamination. ${ }^{7}$

Department of Chemical Engineering, Faculty of Engineering, Lambung Mangkurat University, Banjarbaru 70714, Indonesia. E-mail: ifnata@unlam.ac.id
This issue can be resolved by using a heterogeneous catalyst. Nowadays, researchers are extensively developing biodiesel processes using heterogeneous catalysts. ${ }^{1,7,8}$ Recently, the use of cesium-impregnated sodium zirconate with soybean and jatropha oils has been observed. ${ }^{9}$ Kumar and Ali $^{10}$ reported the transesterification of used cotton seed oil using a Li, Na and $\mathrm{K}$ catalytic process. The utilization of lithium in the transesterification of canola oil has been demonstrated by Alsharifi et al. ${ }^{11}$ High yields of biodiesel were obtained in these studies; but, unfortunately, the developed catalysts still used commercial materials. Heterogeneous catalysts based on commercial materials are still expensive; hence, the development of heterogeneous catalysts from waste materials should be considered.

Hindryawati and Maniam ${ }^{12}$ have demonstrated a prospective waste material as a catalyst, i.e. waste marine sponges, in the ultrasound-assisted transesterification of waste cooking oil. A high yield of biodiesel (98\%) was obtained. However, the ultrasound method uses a large volume of solvent and requires a long reaction time ${ }^{13} \mathrm{Li}$ et al. have utilized a carbide slag waste material as a heterogeneous catalyst for biodiesel production. ${ }^{14}$ However, the yield obtained was about $91 \%$ and they used fresh oil, i.e., soybean oil. Therefore, the utilization of waste materials as a heterogeneous catalyst for biodiesel production is still being developed. $\mathrm{CaO}$ is one of the potential catalysts for biodiesel production. ${ }^{15} \mathrm{CaO}$ catalysts can be formed from a calcination process of $\mathrm{CaCO}_{3}$. A plentiful waste material - eggshell is a potential material, because it contains more than $94 \%$ $\mathrm{CaCO}_{3}{ }^{16}$ Unfortunately, $\mathrm{CaO}$ catalysts have a low surface area of 
about $13 \mathrm{~m}^{2} \mathrm{~g}^{-1},{ }^{17}$ and catalysts with a higher surface area lead to higher biodiesel yields. ${ }^{18}$ To conquer this weakness, the use of a catalyst support such as silica with $\mathrm{CaO}$ catalysts should be considered to increase the surface area of the catalyst. Silica has been widely used as a support for many applications of catalytic reactions. ${ }^{19,20}$

This research aims to produce efficient and low-cost heterogeneous catalysts, i.e., $\mathrm{CaO} / \mathrm{SiO}_{2}$, prepared from eggshell and palm empty fruit bunch (PEFB) waste. Silica for the catalyst support was extracted from palm empty fruit bunches and eggshells were used as the source of $\mathrm{CaO}$. The developed catalyst was used in a transesterification process to produce biodiesel. The characterization of the catalysts using XRD, SEM, BET and FTIR was also performed. The utilization of waste materials as a heterogeneous catalyst for biodiesel production in this work can hopefully reduce the cost of catalyst preparation as compared to the use of commercial catalysts. This is possible due to the abundant availability of palm empty fruit bunches. In addition, waste cooking oil was also used to solve the environmental problem and to promote friendly biodiesel production processes.

\section{Method}

\section{Catalyst preparation}

Eggshells were initially washed twice using distilled water to remove impurities. They were then dried at $90{ }^{\circ} \mathrm{C}$ overnight. The dried material was finely crushed and sieved with a 400-mesh sieve. This material was further named as the fine $\mathrm{CaCO}_{3}$ material. To obtain the $\mathrm{CaO}$ catalyst, the fine $\mathrm{CaCO}_{3}$ material was calcined at $900{ }^{\circ} \mathrm{C}$ for $2 \mathrm{~h}$.

\section{Support preparation}

Palm empty fruit bunches were cleaned of impurities using distilled water and then dried at $100{ }^{\circ} \mathrm{C}$ overnight. The material was then ground into smaller pieces and sieved with a 20 -mesh sieve. The material was further calcined at $700{ }^{\circ} \mathrm{C}$ for $4 \mathrm{~h}$. Ten grams of the calcined material was further extracted using a solution of $60 \mathrm{~mL}$ of $\mathrm{NaOH}$ with various concentrations of $7.5 \%(\mathrm{w} / \mathrm{v}), 10 \%(\mathrm{w} / \mathrm{v})$ and $12.5 \%(\mathrm{w} / \mathrm{v})$ at $80{ }^{\circ} \mathrm{C}$ for $1 \mathrm{~h}$. These concentrations led to sodium hydroxide molarities of $1.87,2.5$ and $3.125 \mathrm{~N}$. Then, $1 \mathrm{~N} \mathrm{HCl}$ was carefully dropped into the obtained filtrate to achieve a solution $\mathrm{pH}$ of 7 ; hence, a silica precipitate was obtained. The precipitate was filtered and heated at $90{ }^{\circ} \mathrm{C}$ overnight. This final material was further named as the $\mathrm{SiO}_{2}$ support.

\section{Catalyst formation}

The fine $\mathrm{CaCO}_{3}$ was impregnated with 4 grams of $\mathrm{SiO}_{2}$ support using $20 \mathrm{~mL}$ of distilled water for $2 \mathrm{~h}$. The ratio of catalyst to support used was $10 \%(\mathrm{w} / \mathrm{w})$ based on the weight of $\mathrm{CaCO}_{3}$ to $\mathrm{SiO}_{2}$, respectively. The solution was then heated at $90{ }^{\circ} \mathrm{C}$ overnight. The obtained solid material was calcined at $900{ }^{\circ} \mathrm{C}$ for $2 \mathrm{~h}$. The final catalyst was further called $\mathrm{CaO} / \mathrm{SiO}_{2}$. The same method was applied for the palm empty fruit bunch material without the extraction process used as a support. This final catalyst was named as $\mathrm{CaO} / \mathrm{PEFB}$. The performance of both catalysts, $\mathrm{CaO} / \mathrm{SiO}_{2}$ and $\mathrm{CaO} / \mathrm{PEFB}$, was compared to a $\mathrm{CaO}$ catalyst without a support as a control.

\section{Transesterification process and biodiesel separation}

A $100 \mathrm{~mL}$ sample of waste cooking oil was placed in a threenecked glass flask. Methanol was carefully poured into the flask with a ratio of methanol to waste cooking oil of 14 molar. The heterogeneous catalyst was added into the flask at a concentration of $8 \%(\mathrm{w} / \mathrm{w})$. The reaction was further carried out for $90 \mathrm{~min}$ at a temperature of $60{ }^{\circ} \mathrm{C}$.

The solution after the reaction process was filtered to separate the solid catalyst from the solution. The catalyst was then washed using distilled water and dried in an oven at $90{ }^{\circ} \mathrm{C}$ for $5 \mathrm{~h}$. The catalyst was reused for the next transesterification reaction. The filtrate was annealed in a funnel overnight to separate the mixture of biodiesel-methanol and glycerol. The biodiesel-methanol mixture was then evaporated to obtain the biodiesel. The biodiesel was identified by using GCMS (2010S Shimadzu, Tokyo, Japan) equipped with a HP-1 capillary column $(\mathrm{ID}=0.25 \mathrm{~mm}$, film $=0.25 \mu \mathrm{m}$, Hewlett-Packard, USA) and connected to a flame ionization detector. Helium was used as the carrier gas at a flow rate of $3 \mathrm{~mL} \mathrm{~min}^{-1}$; the split ratio was 49. The yield of biodiesel was evaluated after the separation process using the method reported elsewhere. ${ }^{21}$

\section{Catalyst characterization}

The $\mathrm{CaO}$ catalyst, silica as the catalyst support and the fresh and used $\mathrm{CaO} / \mathrm{SiO}_{2}$ catalysts were characterized to compare their physical and chemical characteristics. The characterization techniques used for the catalysts included XRD, SEM, BET and FT-IR. XRD (PANalytical X'PERT QUANTIFY, Almelo, Netherlands) was used for phase identification, using copper K-alpha $\left(\mathrm{Cu} \mathrm{K} \alpha\right.$ ) radiation with $2 \theta$ in the range from 10 to $80^{\circ}$ at a scan rate of $2^{\circ} \mathrm{min}^{-1}$. The operation voltage and current were kept at $40 \mathrm{kV}$ and $100 \mathrm{~mA}$, respectively. SEM (Inspect S50, Hillsboro, USA) conducted under an electrical potential of $20 \mathrm{kV}$ at 10000 times magnification, was utilized for the morphological studies. BET (NOVA 1200E, Florida, USA), by applying nitrogen adsorption measurements, was used for observing the surface area. FT-IR (Thermo Scientific Nicolet iS10 FT-IR, Madison, USA), recorded over the range of $500-4000 \mathrm{~cm}^{-1}$, was utilized for structural studies of the bonded chemical compounds.

\section{Results and discussion}

\section{Characterization results}

Fig. 1 shows the results of XRD characterization for the $\mathrm{CaO}$ catalyst, $\mathrm{SiO}_{2}$ support, fresh $\mathrm{CaO} / \mathrm{SiO}_{2}$ catalyst and used $\mathrm{CaO} /$ $\mathrm{SiO}_{2}$ catalyst. The silica used here was produced from the extraction of oil palm empty fruit bunches using $7.5 \% \mathrm{NaOH}$. The presence of $\mathrm{CaO}$ was shown at $2 \theta$ values of approximately $34^{\circ}$ and $64^{\circ} ;^{22}$ meanwhile, $\mathrm{SiO}_{2}$ was found at around $27^{\circ}$ and $48^{\circ} .^{20}$ The existence of a $\mathrm{CaCO}_{3}$ peak at around $30^{\circ}$ (ref. 22) was shown for the $\mathrm{CaO}$ catalyst, indicating that the $\mathrm{CaCO}_{3}$ was not 
completely decomposed into $\mathrm{CaO}$. A high temperature of calcination up to $1000{ }^{\circ} \mathrm{C}$ led to complete decomposition of $\mathrm{CaCO}_{3}$ into $\mathrm{CaO}^{22}$ On the other hand, fewer peaks were observed for the fresh $\mathrm{CaO} / \mathrm{SiO}_{2}$ catalyst. This may be because the crystalline domains were small, and thus not detected by $\mathrm{XRD} .{ }^{23}$ Another possibility is that a new phase, such as $\mathrm{Ca}-\mathrm{Si}-\mathrm{O}$, was formed due to interactions between $\mathrm{CaO}$ and $\mathrm{SiO}_{2}$ on the surface of the catalyst during calcination; hence, their presence could not be detected by XRD. ${ }^{20,24,25}$ This occurrence probably also supported the observation of a lower intensity of the $\mathrm{CaCO}_{3}$ peaks in the $\mathrm{CaO} / \mathrm{SiO}_{2}$ catalyst.

Fig. 2a-d show SEM images for the $\mathrm{CaO}$ catalyst, $\mathrm{SiO}_{2}$ support, fresh $\mathrm{CaO} / \mathrm{SiO}_{2}$ catalyst and used $\mathrm{CaO} / \mathrm{SiO}_{2}$ catalyst, respectively. Fig. 2a shows the structure of the $\mathrm{CaO}$ catalyst without a support, which is like a beehive, ${ }^{26}$ with a catalyst texture wherein the particles are agglomerated. ${ }^{27}$ As shown in Fig. 2b, strong compact particles were observed for the structure of silica. Fig. 2c shows that $\mathrm{CaO}$ was uniformly distributed on the surface of the silica. This supported the previous XRD discussion, as the small crystalline domains of $\mathrm{CaO}$ were observed to spread on the surface of the silica as shown in Fig. 2c. On the other hand, the used $\mathrm{CaO} / \mathrm{SiO}_{2}$ catalyst was likely covered by oil; hence, the peaks for $\mathrm{CaO}$ were reasonably undetected, as also found in the XRD result.

Table 1 shows the surface area results for the $\mathrm{CaO}$ catalyst, $\mathrm{SiO}_{2}$ support, fresh $\mathrm{CaO} / \mathrm{SiO}_{2}$ catalyst and used $\mathrm{CaO} / \mathrm{SiO}_{2}$ catalyst. The pure $\mathrm{CaO}$ catalyst generated in this work had a low surface area, i.e., $2.8 \mathrm{~m}^{2} \mathrm{~g}^{-1}$; this value was close to the commercial one $\left(3 \mathrm{~m}^{2} \mathrm{~g}^{-1}\right)$. Silica showed great potential as a support as it provided a high surface area $\left(39.7 \mathrm{~m}^{2} \mathrm{~g}^{-1}\right)$. The silica surface area obtained here was comparable to those reported in other studies $\left(12-67 \mathrm{~m}^{2} \mathrm{~g}^{-1}\right) .^{28,29}$ The various values of silica surface area depend on the preparation and process of

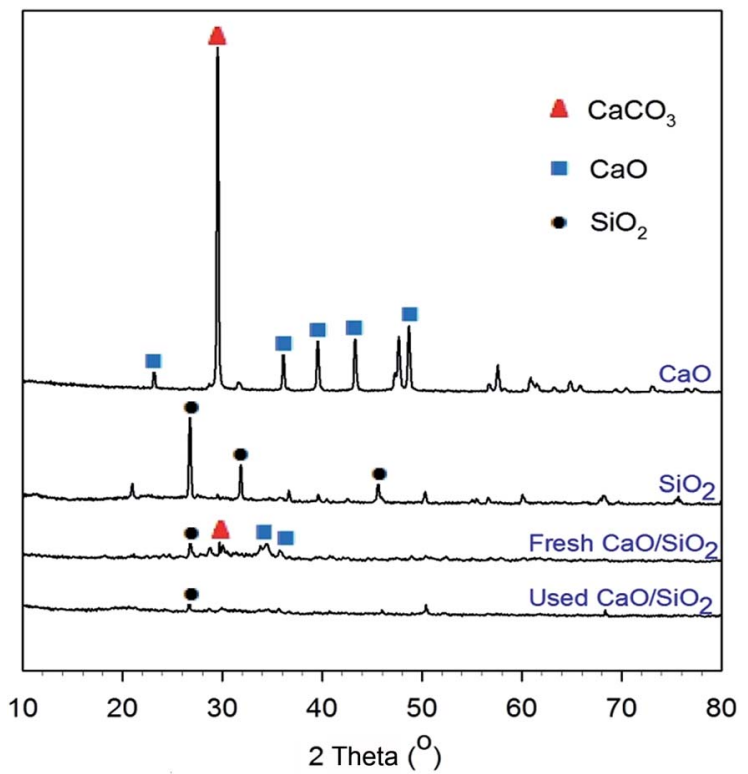

Fig. 1 XRD characterization results for the $\mathrm{CaO}$ catalyst, $\mathrm{SiO}_{2}$ support, fresh $\mathrm{CaO} / \mathrm{SiO}_{2}$ catalyst and used $\mathrm{CaO} / \mathrm{SiO}_{2}$ catalyst.
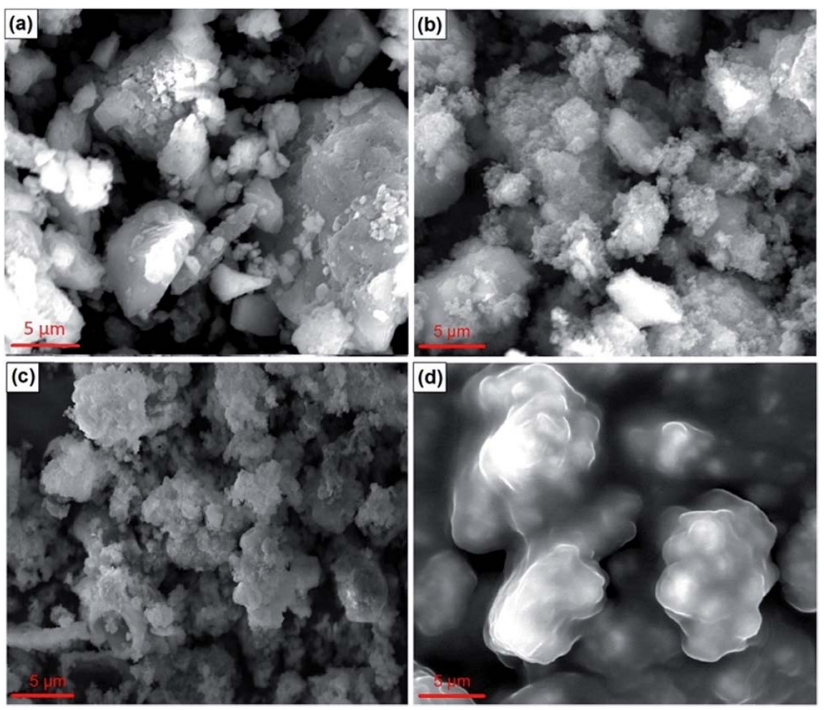

Fig. 2 SEM characterization results of for: (a) $\mathrm{CaO}$, (b) $\mathrm{SiO}_{2}$, (c) $\mathrm{CaO}$ / $\mathrm{SiO}_{2}$ (fresh), and (d) $\mathrm{CaO} / \mathrm{SiO}_{2}$ (used).

Table 1 BET characterization results of catalyst surface area

\begin{tabular}{lll}
\hline Catalyst & $\begin{array}{l}\text { Surface area } \\
\left(\mathrm{m}^{2} \mathrm{~g}^{-1}\right)\end{array}$ & Reference \\
\hline $\mathrm{CaO}$ & 2.8 & This work \\
$\mathrm{Commercial} \mathrm{CaO}$ & 3.0 & 26 \\
$\mathrm{SiO}_{2}$ & 39.7 & This work \\
$\mathrm{SiO}_{2}$ & 12 & 28 \\
$\mathrm{CaO} / \mathrm{SiO}_{2}$ (fresh) & 79.8 & This work \\
$\mathrm{CaO} / \mathrm{SiO}_{2}$ (used) & 3.6 & This work
\end{tabular}

formation. ${ }^{30}$ The $\mathrm{CaO}$ catalyst supported with silica demonstrated a very high surface area, i.e., $79.8 \mathrm{~m}^{2} \mathrm{~g}^{-1}$, as shown in Table 1. Catalysts possessing a high surface area lead to high catalytic activity in biodiesel production..$^{31,32}$ The low surface area for the used $\mathrm{CaO} / \mathrm{SiO}_{2}$ was due to the closure of the catalyst surface by oil, supported by the previous characterization results.

Fig. 3 shows the FT-IR characterization results for the $\mathrm{CaO}$ catalyst, $\mathrm{SiO}_{2}$ support, fresh $\mathrm{CaO} / \mathrm{SiO}_{2}$ catalyst and used $\mathrm{CaO} /$ $\mathrm{SiO}_{2}$ catalyst. The band at $1414 \mathrm{~cm}^{-1}$ for the $\mathrm{CaO}$ catalyst can be attributed to the stretching vibration of surface $\mathrm{CO}_{3}{ }^{2-}$ groups, ${ }^{33}$ indicating the presence of $\mathrm{CaCO}_{3}$. This finding again supported the previous characterization results that the compound was not fully decomposed into $\mathrm{CaO}$. The broad absorption in the range of $700-900 \mathrm{~cm}^{-1}$ can be assigned to $\mathrm{Ca}-\mathrm{O},{ }^{34,35}$ and the broad absorption found here was at about $864 \mathrm{~cm}^{-1}$. The stretching mode region of $\mathrm{Si}-\mathrm{O}$ is assigned to a wavenumber of about $1015 \mathrm{~cm}^{-1},{ }^{36}$ and was clearly observed here for the $\mathrm{SiO}_{2}$ support. For both the fresh and used $\mathrm{CaO} / \mathrm{SiO}_{2}$ catalysts, the two peaks at wavenumbers of $864 \mathrm{~cm}^{-1}$ and $1015 \mathrm{~cm}^{-1}$ assigned to $\mathrm{Ca}-\mathrm{O}$ and $\mathrm{Si}-\mathrm{O}$, respectively, were observed to not separate, and even merged. For the used $\mathrm{CaO} / \mathrm{SiO}_{2}$ catalyst, the bands at around $2933 \mathrm{~cm}^{-1}$ and $2844 \mathrm{~cm}^{-1}$ are attributed to the symmetric and asymmetric stretching vibration of aliphatic 


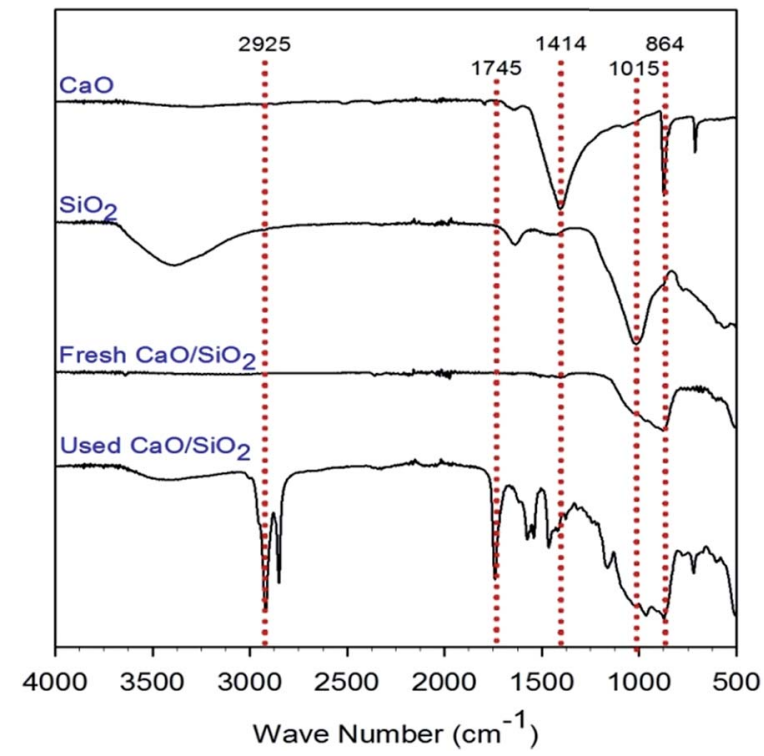

Fig. 3 FT-IR characterization results for $\mathrm{CaO} / \mathrm{SiO}_{2}$ (fresh), $\mathrm{CaO} / \mathrm{SiO}_{2}$, $\mathrm{SiO}_{2}$ extracted and $\mathrm{CaO}$ calcined.

$\mathrm{CH}_{2}$ groups, respectively. ${ }^{33}$ The broad absorption at $1744 \mathrm{~cm}^{-1}$ is assigned to ester carbonyl functional groups of the triglycerides. ${ }^{37}$ These peaks observed for the used $\mathrm{CaO} / \mathrm{SiO}_{2}$ catalyst were obviously due to the presence of oil covering the catalyst; thus, they again confirm the previous characterization results.

\section{Extraction of silica}

Fig. 4 shows the results of silica extraction from oil palm empty fruit bunches. The optimum yield of silica was obtained at the sodium hydroxide concentration of $10 \%$. It was reported that a higher yield of silica extraction from rice hull was obtained by increasing the concentration of sodium hydroxide. ${ }^{38}$ The silica yield in their work was in the range of 35-89\% using a concentration of $0.25-1 \mathrm{~N}$ of $\mathrm{NaOH}$. There is no silica extracted using a concentration of less than $0.25 \mathrm{~N}$ and no improvement in the silica yield for concentrations higher than $1 \mathrm{~N}$. The yields of extraction obtained here were $62.9 \%, 68.2 \%$ and $52.7 \%$ for the utilization of a sodium hydroxide concentration of $7.5 \%, 10 \%$ and $12.5 \%(\mathrm{w} / \mathrm{v})$, respectively.

The lower yield of silica obtained and the higher sodium hydroxide concentration used in this work were attributed to the higher amount of minerals in palm empty fruit bunches compared to rice husk. ${ }^{39}$ The absence of these minerals is an important parameter in the extraction of silica. ${ }^{38}$ At higher concentrations of $\mathrm{NaOH}(12.5 \%)$, less silica was extracted, because the amount of solvent became saturated in the system. Hence, the silica became more difficult to extract.

\section{Transesterification of waste cooking oil}

Fig. 5 shows the result of the transesterification process from waste cooking oil using catalysts of $\mathrm{CaO}$, fresh $\mathrm{CaO} / \mathrm{SiO}_{2}, \mathrm{CaO} /$ PEFB and used $\mathrm{CaO} / \mathrm{SiO}_{2}$ (after 3 cycles). The $\mathrm{CaO}$ catalyst prepared from eggshells was capable of producing biodiesel

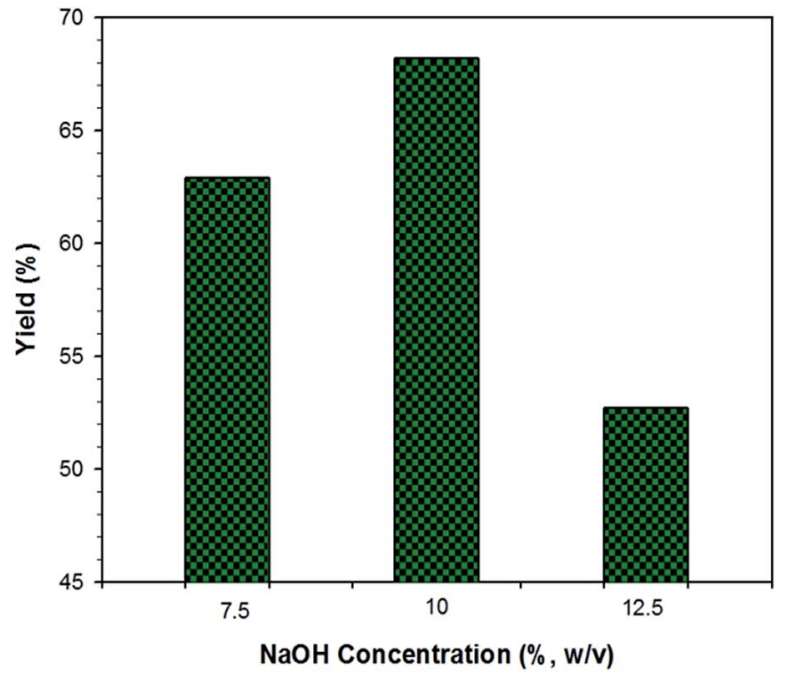

Fig. 4 Yield of silica extraction from empty fruit bunches.

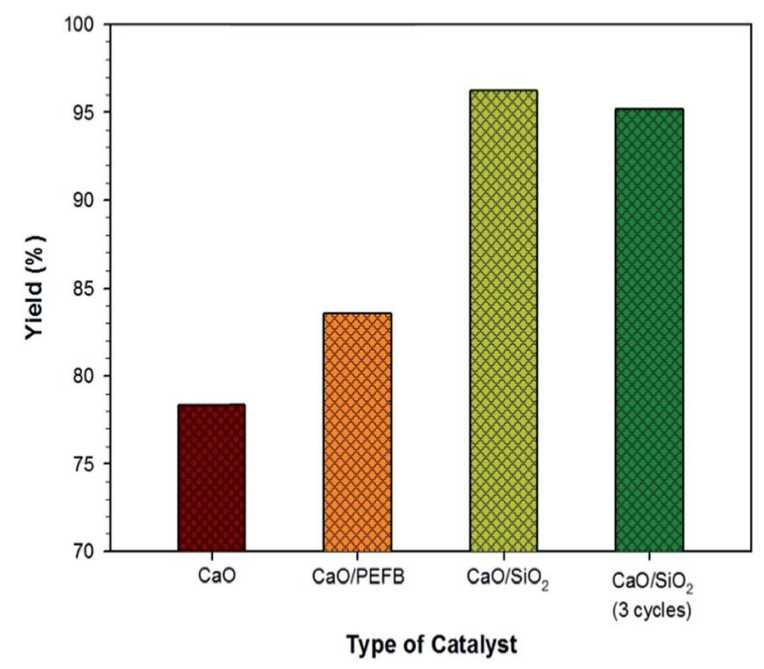

Fig. 5 Transesterification of waste cooking oil for biodiesel production.

with a yield of $78 \%$; this shows that eggshell waste is a prospective source of catalysts for biodiesel applications. On the addition of a support to the catalyst, the yield of biodiesel was increased to $96 \%$. This increase in yield was related to the increase in the surface area of the catalyst. ${ }^{18}$ A higher surface area leads to the improvement of the catalyst activity, ${ }^{\mathbf{4 0}}$ thus accelerating reactions on the surface of the catalyst.

The reusability and stability are also important parameters for biodiesel production to be economically feasible when applied on an industrial scale. ${ }^{41}$ The $\mathrm{CaO} / \mathrm{SiO}_{2}$ catalyst after three runs showed an insignificant change in performance with a decrease in yield of only $1 \%$. In previous reports, the decrease in yield after three cycles was substantial for $\mathrm{CaO}$ catalysts at up to $5-20 \%{ }^{41-43}$ To eliminate the extraction process and the usage of chemicals and energy, the $\mathrm{CaO}$ was directly supported on palm empty fruit bunch powder via an impregnation method. As 
compared to the $\mathrm{CaO}$ catalyst, the performance of $\mathrm{CaO} / \mathrm{PEFB}$ was slightly enhanced from $78 \%$ to $83 \%$.

Fig. 6 shows a chromatogram of the biodiesel product produced using the $\mathrm{CaO} / \mathrm{SiO}_{2}$ catalyst. The components of

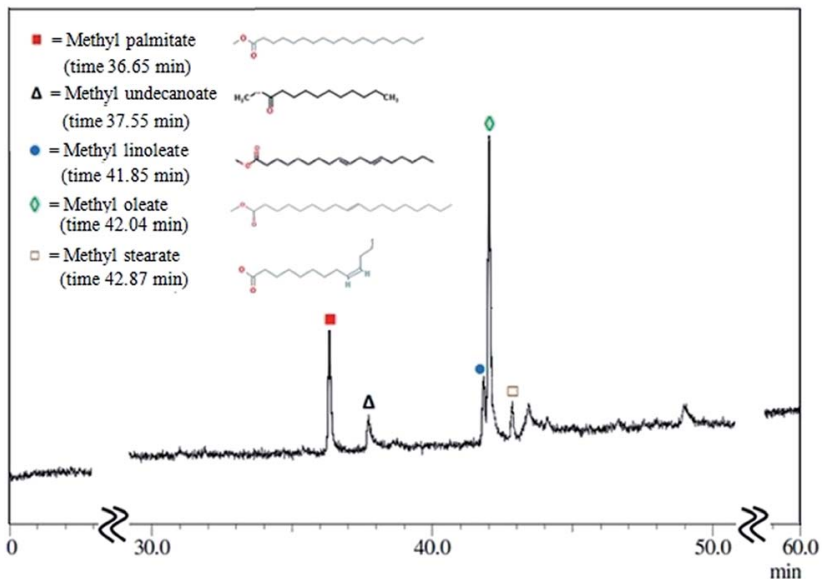

Fig. 6 Chromatogram of GC-MS analysis for the biodiesel product. methyl palmitate $\left(\mathrm{C}_{17}\right)$, methyl 11-cyclohexylundecanoate $\left(\mathrm{C}_{18}\right)$, methyl linoleate $\left(\mathrm{C}_{19}\right)$, methyl oleate $\left(\mathrm{C}_{19}\right)$ and methyl stearate $\left(\mathrm{C}_{19}\right)$ are present in the biodiesel with mole percentages of $22.55 \%, 4.44 \%, 10.90 \%, 53.41 \%$ and 5.69\%, respectively (Table $2)$. The biodiesel generally produced through direct transesterification processes contains fatty acids in the range of $\mathrm{C}_{16}{ }^{-}$ $\mathrm{C}_{20} ;{ }^{\mathbf{4 4 - 4 6}}$ the biodiesel obtained here was consistent with the previous literature in terms of fatty acid type. On the other hand, the composition of biodiesel is also associated with the source of natural oil used, ${ }^{47}$ because many factors such as soil characteristics, plant maturity, climate and genetics of the plant affect the fatty acid composition. It has also been reported that the fatty acid composition in biodiesel produced via direct trans-esterification from various vegetable oils is typically in the range of $\mathrm{C}_{15}-\mathrm{C}_{24} \cdot{ }^{48-50}$

\section{Comparison of various catalyst types}

Table 3 presents a comparison of several types of catalysts utilized for biodiesel production using waste cooking oil. As shown in work \#1, biodiesel could be produced using a homogeneous catalyst; however, the yield is still below $90 \%$. To reduce the formation of foam due to a high FFA (free fatty

Table 2 Fatty acid composition in the biodiesel product

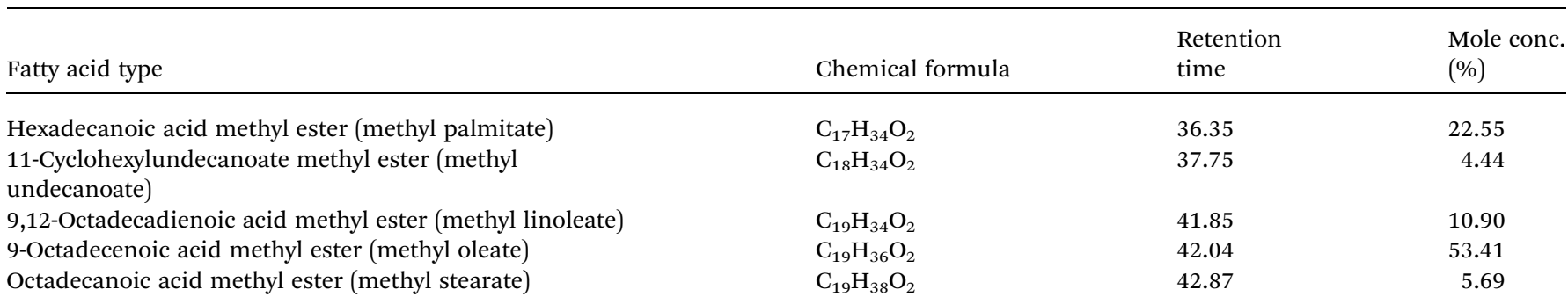

Table 3 Comparison of various types of catalysts used in the transesterification of waste cooking oil as a feedstock

\begin{tabular}{|c|c|c|c|c|c|c|c|}
\hline Work number & Catalyst & $\begin{array}{l}\text { Temperature } \\
\left({ }^{\circ} \mathrm{C}\right)\end{array}$ & Time (h) & Molar ratio $^{a}$ & $\begin{array}{l}\text { Yield } \\
(\%)\end{array}$ & Reference & Remarks \\
\hline$\# 1$ & $\mathrm{KOH}$ & 87 & 2 & $9: 1$ & 87 & 51 & $\begin{array}{l}\text { Homogeneous catalyst. } \\
\text { Soap formation }\end{array}$ \\
\hline$\# 2$ & $\begin{array}{l}\text { Ferric sulphate followed } \\
\text { by KOH }\end{array}$ & 100,100 & 2,2 & $9: 1,7.5: 1$ & 96 & 52 & $\begin{array}{l}\text { Mixture of homogeneous } \\
\text { and heterogeneous }\end{array}$ \\
\hline$\# 4$ & Zinc stearate & 200 & 10 & $18: 1$ & 98 & & Commercial chemical \\
\hline$\# 5$ & $\mathrm{Zr}_{0.7} \mathrm{H}_{0.2} \mathrm{PW}_{12} \mathrm{O}_{40}$ & 65 & 8 & $20: 1$ & 98.9 & 54 & Commercial chemical \\
\hline$\# 6$ & $\mathrm{MgO} / \mathrm{TiO}_{2}$ & 150 & 6 & $30: 1$ & 91.6 & 55 & Commercial chemical \\
\hline$\# 7$ & $\mathrm{Sr} / \mathrm{ZrO}_{2}$ & 115 & 1.45 & $29: 1$ & 79.7 & 56 & Commercial chemical \\
\hline$\# 8$ & Golden apple snail & 60 & 1 & $18: 1$ & 83 & 57 & Waste material \\
\hline$\# 9$ & Mereterix venus & 60 & 1 & $18: 1$ & 78 & 57 & Waste material \\
\hline
\end{tabular}

\footnotetext{
${ }^{a}$ Methanol: waste cooking oil (WCO).
} 
acid) content, and thus consequently increase the yield, a mixed process (work \#2) of using homogeneous acid and heterogeneous base catalysts was used. An improvement in the yield (96\%) was observed. Nevertheless, the process requires a costly separation process. Work numbers \#3, \#4 and \#5 show transesterification processes using commercial materialbased heterogeneous catalysts, with potential yields in the range of 79.7-98.9\% being observed. The reactions were processed at high temperature and mol ratio of reactant. It has been reported that reaction processes using such mixed oxide catalysts require high temperatures and pressures during the process. ${ }^{60}$ Moreover, the commercial catalysts are not cheap. This will consequently increase the cost of biodiesel production and its sale, thus limiting biodiesel applications on a larger scale over other potential catalysts. ${ }^{61}$ Therefore, it is highly recommended to use waste materials as heterogeneous catalysts in biodiesel production. Potential waste materials including golden apple snails, mereterix venus, chicken bone and mereterix mereterix (clamshell) as heterogeneous catalysts utilized in biodiesel production were reported in work numbers \#8, \#9, \#10 and \#11. The obtained yields of biodiesel were still below $90 \%$, and the values were comparable to those of our work (\#12). It has been reported that only a few waste materials can be employed for biodiesel production from a waste cooking oil type of feedstock. ${ }^{62}$ This is because the high content of FFAs in WCO contributes to a reduction in biodiesel yield. As recently reported by Tshizanga et al., ${ }^{63}$ a higher surface area catalyst could significantly mediate the transesterification of WCO containing a high FFA content. Therefore, here the presence of silica in the $\mathrm{CaO}$ catalyst resulted in a significant increase in the yield of biodiesel (\#13), associated with the high surface area obtained. This reveals that such heterogeneous catalysts sourced from waste materials will always be of major interest in the development of biodiesel production processes.

\section{Future work}

The developed catalyst obtained in this work showed a number of potential results in increasing the yield of biodiesel. Moreover, the palm empty fruit bunch and eggshell waste materials are abundantly available. The activated PEFB could also be directly used as the support of a CaO catalyst. Bearing in mind that biodiesel production was achieved without a chemical extraction process and the amount of $\mathrm{CaO}$ was only one-tenth the amount of PEFB, this catalyst is a prospective material to be applied on an industrial scale. For this, it is strongly recommended that a pilot plant and the economic feasibility of the catalysts be studied in future work. Because the raw materials for the developed catalysts and the used oils are waste materials, the policy of waste usage and its collection should also be supported by the government of each country. In addition, the biodiesel production process should be developed to not only reduce the cost of the process (by using a heterogeneous catalyst without chemical processes of separation) but also minimize the waste-related environmental issues. ${ }^{64}$

\section{Conclusions}

Silica as a support for a $\mathrm{CaO}$ catalyst could be extracted from palm empty fruit bunches (PEFBs). The presence of a silica support in the $\mathrm{CaO}$ catalyst significantly increased the surface area from 2.8 to $79.8 \mathrm{~m}^{2} \mathrm{~g}^{-1}$. This resulted in an improvement in the biodiesel yield from 78 to $96 \%$. Three cycles of catalyst use led to only a $1 \%$ drop in the biodiesel yield. The $\mathrm{CaO}$ catalyst supported on activated PEFB resulted in an improvement in the biodiesel yield from 78 to $83 \%$.

\section{Conflicts of interest}

There are no conflicts to declare.

\section{Abbreviations}

$\begin{array}{ll}\mathrm{BET} & \text { Brunauer, Emmett and Teller } \\ \mathrm{CaCO}_{3} & \text { Calcium carbonate } \\ \mathrm{CaO} & \text { Calcium oxide } \\ \text { FFA } & \text { Free fatty acid } \\ \text { FT-IR } & \text { Fourier-transform infrared spectroscopy } \\ \text { GCMS } & \text { Gas chromatography mass spectrometry } \\ \mathrm{K}_{3} \mathrm{PO}_{4} & \text { Potassium phosphate } \\ \mathrm{KOH} & \text { Potassium hydroxide } \\ \mathrm{MgO} & \text { Magnesium oxide } \\ \mathrm{NaOH} & \text { Sodium hydroxide } \\ \mathrm{PEFB} & \text { Palm empty fruit bunch } \\ \mathrm{SEM} & \text { Scanning electron microscope } \\ \mathrm{SiO}_{2} & \text { Silicon dioxide } \\ \mathrm{Sr}_{\mathrm{TiO}} & \text { Strontium } \\ \mathrm{WCO}_{\mathrm{XRD}} & \text { Titanium dioxide } \\ \mathrm{ZrO}_{2} & \text { Waste cooking oil } \\ \end{array}$

\section{Acknowledgements}

The authors extend their appreciation to the Faculty of Engineering, Lambung Mangkurat University, which provided a Research Grant under contract No. 440/UN8.1.31/KU/2016, for their generous support and funding of this study.

\section{References}

1 S. Wang, C. Zhao, R. Shan, Y. Wang and H. Yuan, Energy Convers. Manage., 2017, 139, 89-96.

2 F. Ullah, L. Dong, A. Bano, Q. Peng and J. Huang, J. Energy Inst., 2016, 89, 282-292.

3 L. F. Chuah, J. J. Klemeš, S. Yusup, A. Bokhari and M. M. Akbar, J. Cleaner Prod., 2017, 146, 181-193.

4 R. L. Naylor and M. M. Higgins, Renewable Sustainable Energy Rev., 2017, 77, 695-705.

5 M. A. Ahmad Farid, M. A. Hassan, Y. H. Taufiq-Yap, M. L. Ibrahim, M. R. Othman, A. A. M. Ali and Y. Shirai, Renewable Energy, 2017, 114, 638-643. 
6 N. Sano, K. Yamada, S. Tsunauchi and H. Tamon, Chem. Eng. J., 2017, 307, 135-142.

7 G. Chen, R. Shan, J. Shi, C. Liu and B. Yan, Energy Convers. Manage., 2015, 98, 463-469.

8 I. F. Nata, M. D. Putra, C. Irawan and C.-K. Lee, J. Environ. Chem. Eng., 2017, 5, 2171-2175.

9 D. A. Torres-Rodríguez, I. C. Romero-Ibarra, I. A. Ibarra and H. Pfeiffer, Renewable Energy, 2016, 93, 323-331.

10 D. Kumar and A. Ali, Energy Fuels, 2010, 24, 2091-2097.

11 M. Alsharifi, H. Znad, S. Hena and M. Ang, Renewable Energy, 2017, 114, 1077-1089.

12 N. Hindryawati and G. P. Maniam, Ultrason. Sonochem., 2015, 22, 454-462.

13 P. Cintas, S. Mantegna, E. C. Gaudino and G. Cravotto, Ultrason. Sonochem., 2010, 17, 985-989.

14 F.-J. Li, H.-Q. Li, L.-G. Wang and Y. Cao, Fuel Process. Technol., 2015, 131, 421-429.

15 N. Asikin-Mijan, H. V. Lee, J. C. Juan, A. R. Noorsaadah and Y. H. Taufiq-Yap, RSC Adv., 2017, 7, 46445-46460.

16 M. J. Quina, M. A. R. Soares and R. Quinta-Ferreira, Resour., Conserv. Recycl., 2017, 123, 176-186.

17 M. Kouzu, T. Kasuno, M. Tajika, Y. Sugimoto, S. Yamanaka and J. Hidaka, Fuel, 2008, 87, 2798-2806.

18 K. Jacobson, R. Gopinath, L. C. Meher and A. K. Dalai, Appl. Catal., B, 2008, 85, 86-91.

19 M. D. Putra, S. M. Al-Zahrani and A. E. Abasaeed, J. Ind. Eng. Chem., 2012, 18, 1153-1156.

20 M. D. Putra, M. K. Al-Mesfer, A. E. Abasaeed and S. M. AlZahrani, J. Chem. Eng. Jpn., 2013, 46, 389-395.

21 G. K. Ayetor, A. Sunnu and J. Parbey, Alexandria Eng. J., 2015, 54, 1285-1290.

22 Z. Wei, C. Xu and B. Li, Bioresour. Technol., 2009, 100, 28832885.

23 E. V. Kondratenko and M. Baerns, Appl. Catal., A, 2001, 222, 133-143.

24 J.-y. Jing, S.-d. Wang, X.-w. Zhang, Q. Li and W.-y. Li, J. Fuel Chem. Technol., 2017, 45, 956-962.

25 M. D. Putra, S. M. Al-Zahrani and A. E. Abasaeed, J. Energy Chem., 2013, 22, 778-782.

26 S. Niju, K. M. Meera, S. Begum and N. Anantharaman, J. Saudi Chem. Soc., 2014, 18, 702-706.

27 C. Chi, Y. Li, X. Ma and L. Duan, Chem. Eng. J., 2017, 326, 378-388.

28 S. Faramawy, A. Y. El-Naggar, A. M. El-Fadly, S. M. ElSabagh and A. A. Ibrahim, Arabian J. Chem., 2016, 9, S765-S775.

29 S. Katoh, M. Imada, N. Takeda, T. Katsuda, H. Miyahara, M. Inoue and S. Nakamura, J. Chromatogr. A, 2007, 1161, 36-40.

30 A. Galarneau, N. Calin, J. Iapichella, M. Barrande, R. Denoyel, B. Coasne and F. Fajula, Chem. Mater., 2009, 21, 1884-1892.

31 X. Liu, X. Piao, Y. Wang, S. Zhu and H. He, Fuel, 2008, 87, 1076-1082.

32 M. P. Dorado, E. Ballesteros, M. Mittelbach and F. J. López, Energy Fuels, 2004, 18, 1457-1462.
33 S. Yan, M. Kim, S. O. Salley and K. Y. S. Ng, Appl. Catal., A, 2009, 360, 163-170.

34 A. K. Parchur and R. S. Ningthoujam, Dalton Trans., 2011, 40, 7590-7594.

35 H. Zaitan, D. Bianchi, O. Achak and T. Chafik, J. Hazard. Mater., 2008, 153, 852-859.

36 P. C. Ricci, G. Gulleri, F. Fumagalli, C. M. Carbonaro and R. Corpino, Appl. Surf. Sci., 2013, 265, 470-474.

37 L. Yang, H. Dai, A. Yi, B. Lin and G. Li, J. Therm. Anal. Calorim., 2008, 93, 875-879.

38 U. Kalapathy, A. Proctor and J. Shultz, Bioresour. Technol., 2000, 73, 257-262.

39 N. A. Sari, C. F. Ishak and R. A. Bakar, Am. J. Agric. Biol. Sci., 2014, 9, 450-456.

40 T.-H. Đặng, B.-H. Chen and D.-J. Lee, J. Taiwan Inst. Chem. Eng., 2017, 79, 14-22.

41 P. R. Pandit and M. H. Fulekar, J. Environ. Manage., 2017, 198, 319-329.

42 L. M. Correia, J. A. Cecilia, E. Rodríguez-Castellón, C. L. Cavalcante Jr and R. S. Vieira, J. Chem., 2017, 2017, 5679512.

43 Y. H. Taufiq-Yap, H. V. Lee, M. Z. Hussein and R. Yunus, Biomass Bioenergy, 2011, 35, 827-834.

44 R. W. Jenkins, N. E. Stageman, C. M. Fortune and C. J. Chuck, Energy Fuels, 2014, 28, 1166-1174.

45 N. Kondamudi, S. K. Mohapatra and M. Misra, J. Agric. Food Chem., 2008, 56, 11757-11760.

46 Y. Liu, Q. Tu, G. Knothe and M. Lu, Fuel, 2017, 199, 157161.

47 A. Abdullah, R. N. Rahmawati Sianipar, D. Ariyani and I. F. Nata, Sustainable Environ. Res., 2017, 27, 291-295.

48 M. Farooq, A. Ramli and D. Subbarao, J. Cleaner Prod., 2013, 59, 131-140.

49 M. Yadav, V. Singh and Y. C. Sharma, Energy Convers. Manage., 2017, 148, 1438-1452.

50 S. S. Satputaley, D. B. Zodpe and N. V. Deshpande, J. Energy Inst., 2017, 90, 513-521.

51 A. Demirbas, Energy Convers. Manage., 2009, 50, 923-927.

52 P. Patil, S. Deng, J. Isaac Rhodes and P. J. Lammers, Fuel, 2010, 89, 360-364.

53 G. Guan, K. Kusakabe and S. Yamasaki, Fuel Process. Technol., 2009, 90, 520-524.

54 X. Zhang, J. Li, Y. Chen, J. Wang, L. Feng, X. Wang and F. Cao, Energy Fuels, 2009, 23, 4640-4646.

55 Z. Wen, X. Yu, S.-T. Tu, J. Yan and E. Dahlquist, Bioresour. Technol., 2010, 101, 9570-9576.

56 W. N. N. Wan Omar and N. A. Saidina Amin, Biomass Bioenergy, 2011, 35, 1329-1338.

57 N. Viriya-empikul, P. Krasae, B. Puttasawat, B. Yoosuk, N. Chollacoop and K. Faungnawakij, Bioresour. Technol., 2010, 101, 3765-3767.

58 M. Farooq, A. Ramli and A. Naeem, Renewable Energy, 2015, 76, 362-368.

59 P. Nair, B. Singh, S. N. Upadhyay and Y. C. Sharma, J. Cleaner Prod., 2012, 29-30, 82-90.

60 Y. C. Sharma, B. Singh and J. Korstad, Fuel, 2011, 90, 13091324. 
61 L. Bournay, D. Casanave, B. Delfort, G. Hillion and J. A. Chodorge, Catal. Today, 2005, 106, 190-192.

62 S. H. Y. S. Abdullah, N. H. M. Hanapi, A. Azid, R. Umar, H. Juahir, H. Khatoon and A. Endut, Renewable Sustainable Energy Rev., 2017, 70, 1040-1051.
63 N. Tshizanga, E. F. Aransiola and O. Oyekola, S. Afr. J. Chem. Eng., 2017, 23, 145-156.

64 K. Shahzad, A. S. Nizami, M. Sagir, M. Rehan, S. Maier, M. Z. Khan, O. K. M. Ouda, I. M. I. Ismail and A. O. BaFail, PLoS One, 2017, 12, e0171297. 